ORIGINAL ARTICLE

\title{
$\beta$-Amyloid 1-42 induces physiological transcriptional regulation of BACE1
}

\author{
Alessandra Piccini,* Roberta Borghi,* Michela Guglielmotto, $\dagger \ddagger$ \\ Elena Tamagno, $\dagger+$ Gabriella Cirmena,* Anna Garuti,* Valeria Pollero, $\S$ \\ Sergio Cammarata, $\S$ Michele Fornaro, II Massimo Messa,** \\ Laura Colombo, ${ }^{* *}$ Mario Salmona, ${ }^{* *}$ George Perry $\dagger \dagger$ and \\ Massimo Tabaton* \\ *Department of Internal Medicine and Medical Specialities, University of Genova, Genova, Italy \\ $\dagger$ Department of Experimental Medicine and Oncology, General Pathology Section, University of \\ Torino, Torino, Italy \\ $\ddagger$ Neuroscience Institute of the Cavalieri Ottolenghi Foundation (NICO), University of Torino, \\ Orbassano (Torino), Italy \\ $\S$ Department of Neurology, Galliera Hospital, Genova, Italy \\ IIDepartment of Neurosciences, Ophtalmology and Genetics, University of Genova, Genova, Italy \\ **Department of Molecular Biochemistry and Pharmacology, Mario Negri Research Institute, Milan, \\ Italy \\ $\dagger+$ College of Sciences, University of Texas at San Antonio, San Antonio, Texas, USA
}

\section{Abstract}

The pathogenesis of Alzheimer's disease $(A D)$ is only partially understood. $\beta$-amyloid $(A \beta)$ is physiologically generated by sequential cleavage of its precursor protein by the $\beta$ - and the $\gamma$-secretase and it is normally disposed of. In Alzheimer's disease, $A \beta$ is excessively produced or less dismissed, but the hypothesis on its physiological and pathological role are heterogeneous and often discordant. It has been described a positive feedback loop from the $\gamma$ - to the $\beta$-secretase cleavages of $A \beta$ precursor protein, which is activated by mutations of Presenilin 1 (PS1), the catalytic core of the $\gamma$-secretase. These findings show that $A \beta$ precursor protein as well the activity of the $\gamma$-secretase are required to obtain the up-regulation of $\beta$-secretase which is induced by Prese- nilin 1 mutations. Then, $A \beta 1-42$ is the $A \beta$ precursor protein derivative that up-regulates the expression of $\beta$-secretase, and $\mathrm{c}$-jun $\mathrm{N}$-terminal kinase (JNK)/C-Jun and ERK $1 / 2$ are involved. Here, we describe the activation of $\beta$-secretase and $c$-jun $\mathrm{N}$-terminal kinase related proteins by monomeric $A \beta$ $1-42$, defining the conditions that most efficiently strike the described signaling without producing toxicity. Taken together these data imply that monomeric $A \beta 1-42$, at nontoxic concentrations and time frames, are able to induce a signaling pathway that leads to transcriptional activation of $\beta$-secretase.

Keywords: $\beta$-amyloid, $\beta$-secretase, $\gamma$-secretase, aggregation, Alzheimer's disease, Presenilins.

J. Neurochem. (2012) 122, 1023-1031.
The major pathologic event of Alzheimer's disease (AD) is the accumulation in the brain of $\beta$-amyloid $(A \beta)$, heterogeneous peptide that result from the sequential cleavages operated on the $\beta$-amyloid precursor protein (APP) by the $\beta$-secretase (BACE 1) and the $\gamma$-secretase (Selkoe 2001). The altered activity of both endo-proteases is involved in the pathogenesis of AD. Presenilin 1 (PS1) is the catalytic subunit of the $\gamma$-secretase. Mutations of PS1 gene, that are
Received April 18, 2012; revised manuscript received June 7, 2012; accepted June 7, 2012.

Address correspondence and reprint requests to Massimo Tabaton, Department of Internal Medicine and Medical Specialities, University of Genova, Viale Benedetto XV 6, 16132 Genova, Italy.

E-mail: mtabaton@neurologia.unige.it

Abbreviations used: $\mathrm{A} \beta, \beta$-amyloid; $\mathrm{AD}$, Alzheimer's disease; APP, $\beta$-amyloid precursor protein; BACE 1, $\beta$-secretase; JNK, c-jun N-terminal kinase; PS1, Presenilin 1. 
the major cause of early-onset familial AD, induce an altered $\gamma$-secretase cleavage, leading to a relative increased production of A $\beta 42$ species (Citron et al. 1997). The activity of BACE1 is augmented in the brain of sporadic AD (Holsinger et al. 2002; Yang et al. 2003). Oxidative stress (Tamagno et al. 2002) and hypoxia (Sun et al. 2006) are causes of the increased BACE1 activity. We, and other research groups, have shown that oxidant agents and 4-hydroxynonenal produce in vitro an over-expression of BACE1 (Tamagno et al. 2002; Kao et al. 2004). Then, we have demonstrated that the increase in oxidative products is significantly correlated with the increase in BACE1 activity in cerebral cortex of sporadic AD (Borghi et al. 2007). Studying the mechanism of the up-regulation of BACE1 induced by oxidative stress we discovered that the activation of BACE1 is regulated by the activity of the $\gamma$-secretase, and it requires an APP derivative that results from the $\gamma$-secretase cleavage (Tamagno et al. 2008). Furthermore, we have shown that oxidative stress induces the up-regulation of BACE1 expression via the activation of the c-jun $\mathrm{N}$-terminal kinase (JNK) pathway, whereas ERK opposes this effect (Tamagno et al. 2009). Our findings show that a positive feed-back loop from the $\gamma$-secretase to the $\beta$-secretase cleavages of APP is induced not only by oxidative stress but also by PS1 mutations, and that $\mathrm{A} \beta 1-42$ is the product of the $\beta$-secretase cleavage that up-regulates BACE1 expression (Giliberto et al. 2009). The effect of $\mathrm{A} \beta$ 1-42 on BACE1 gene transcription is mediated by the $\mathrm{JNK} / \mathrm{c}$-jun signaling pathway (Guglielmotto et al. 2011). Moreover, it has been determined an $\mathrm{A} \beta$ interacting domain in the promoters of $\mathrm{AD}$-associated genes, suggesting a novel $A \beta$ activity as a putative transcription factor (Maloney and Lahiri 2011). This suggests that a signaling pathway may be active, starting from $A \beta$ 142 and ending on the BACE1 promoter. BACE1 promoter is a very complex one, and the expression of BACE1 is likely to be tightly regulated (Sambamurti et al. 2004).

$\mathrm{A} \beta$ is the subject and object of pathways leading to cell death or survival, where it could play a role not just as a toxic compound, but as a functional signaling intermediate. The hypothesis of an $\mathrm{A} \beta$ physiological and pathological role could rely on its effects at different concentrations, aggregation states, and timing of exposure. Amyloidogenic peptides produce solutions with heterogeneity of molecular species, responsible for affecting the reproducibility of experiments. Manzoni et al. (2009) have recently established a procedure to obtain repeatable physiochemical and biological features of $A \beta$ peptides.

Aggregated $A \beta$ leads to neuronal damage by inducing oxidative stress (Chauhan and Chauhan 2006), impairing membrane integrity (Kirkitadze and Kowalska 2005), and triggering cellular signaling leading to apoptosis (Di Carlo 2010). But $A \beta$ both increases or impairs synaptic activity (Kamenetz et al. 2003; Abramov et al. 2009), and this paradox is likely depending from different composition, aggregation state, and time of exposure of the molecule.
Then, different $A \beta$ peptides, full length or truncated at the Nor C-terminals, at low concentrations and for short time frames, interact with and activate several membrane receptors, e.g. TrkA and p75NTR (Bulbarelli et al. 2009), APP itself (Verdier et al. 2004), RAGE (Yan et al. 2009), insulin receptor (Townsend et al. 2007), acetylcholine receptors (Parri and Dineley 2010), leading to signaling cascades that involve the MAPK pathway, NFKB, and more, possibly controlling gene expression. This signaling action could represent a physiological role of $A \beta$ and/or subtly contribute to the pathogenesis of $\mathrm{AD}$ long before the formation of plaques.

\section{Materials and methods}

Monomer and oligomer characterization

A $\beta$ 1-42 (DAEFRHDSGYEVHHQKLVFFAEDVGSNKGAIIGL MVGGVVIA) was prepared by solid phase peptide synthesis (SPPS) on a 433A synthesizer (Applied Biosystems, Foster City, CA, USA) using Fmoc-protected L-amino acid derivatives, NOVASYN-TGA resin, and a $0.1 \mathrm{mM}$ scale. After the synthesis, the peptide was treated as previously described to obtained monomers and oligomers (Manzoni et al. 2009). This approach allows to obtain batches peptide content at constant of monomers or monomers and oligomers of low-molecular weight.

Atomic force microscopy (AFM) was carried out on a Multimode AFM with a Nanoscope V system operating in Tapping Mode using standard phosphorus-doped silicon probes (Veeco/Digital Instruments, Mannheim, Germany). The scan rate was tuned proportionally to the area scanned and was kept in the $0.5-1.2 \mathrm{~Hz}$ range. Peptide samples were diluted to $5 \mu \mathrm{M}$ with $10 \mathrm{mM} \mathrm{PB}$, and $60 \mu \mathrm{L}$ aliquots were immediately spotted onto a freshly cleaved muscovite mica disk and incubated for 0.5 min. The disk was then washed with $\mathrm{H}_{2} \mathrm{O}$ and dried under a gentle nitrogen stream. All the topographic patterns described in the text were confirmed by additional measurements in a minimum of five different, well-separated areas. The data processing of AFM images were handled using Scanning Probe Image Processor (SPIP-version-5.1.6 released 13 April 2011) data analysis package (Nanoscience Instruments, Phoenix, AZ, USA).

\section{Circular dichroism (CD)}

Monomers and oligomers peptide solutions were diluted to give a final concentration of $25 \mu \mathrm{M}$ with $50 \mathrm{mM}$ phosphate buffered, $150 \mathrm{mM} \mathrm{NaCl}, \mathrm{pH}$ 7.4. The CD spectra were collected on a Jasco J-815 spectropolarimeter (Jasco, Easton, MD, USA ) at $4^{\circ} \mathrm{C}$ from 190 to $260 \mathrm{~nm}$ ( $1.0 \mathrm{~nm}$ band width, and $0.1 \mathrm{~nm}$ resolution) using a $0.1 \mathrm{~cm}$ path length quartz cell. Generally, a sensitivity of $100 \mathrm{mdeg}$, a response of $16 \mathrm{~s}$, a scan speed of $20 \mathrm{~nm} / \mathrm{min}$, and four accumulations were used. CD spectra were expressed as mean molar ellipticity.

\section{Transmission electron microscopy (TEM)}

Ten microliters of monomers or oligomers solutions was dropped onto nickel formvar-carbon coated 200 mesh electron microscopy grids (Electron Microscopy Science, Hatfield, PA, USA) and after $5 \mathrm{~min}$ the solution was removed. Samples were stained for $5 \mathrm{~min}$ with a saturated solution of uranyl acetate, as described previously (Gobbi et al. 2006). Electron microscopy analyses were done with a Libra 120 transmission electron microscope (Carl Zeiss SMT, 
Gottingen, Germany) operating at $120 \mathrm{kV}$ equipped with a Proscan Slow Scan CCD camera (Carl Zeiss SMT).

\section{Cell culture and transfection}

SH-SY5Y cells were cultured in RPMI 1640 (Euroclone, Milan, Italy) supplemented with $10 \%(\mathrm{v} / \mathrm{v})$ fetal bovine serum, $100 \mathrm{U} / \mathrm{mL}$ penicillin, $100 \mu \mathrm{g} / \mathrm{mL}$ streptomycin, $2 \mathrm{mM}$ L-glutamine, $1 \%$ nonessential amino acids, and $1 \%$ sodium pyruvate. Mouse embryonic fibroblast (MEFs) wt and JNK1/2dko (provided by Roger Davis, University of Massachusetts, Worcester, MA, USA) were cultured in low glucose Dulbecco's modified Eagle's medium containing $2 \mathrm{mM}$ glutamine and supplemented with $100 \mathrm{~mL} / \mathrm{L}$ fetal bovine serum, $10 \mathrm{~mL} / \mathrm{L}$ non-essential amino acids, and $10 \mathrm{~mL} / \mathrm{L}$ antibiotic mixture (penicillin-streptomycin-amphotericin), in a humidified atmosphere at $37^{\circ} \mathrm{C}$ with $5 \% \mathrm{CO}_{2}$. Cells were transiently transfected with empty vector (pcDNA3), wild type JNK, and a dominant negative of JNK (negative control) using Lipofectamine 2000 (Life Technologies, Grand Island, NY, USA) according to the manufacturer's instructions.

\section{Treatment of cultured cells with $A \beta$ peptides}

To obtain reproducible and certain $A \beta$ conformations, we will use a preparation procedure that consists on the sequential use of trifluoroacetic acid, formic acid, and sodium hydroxide solutions that disaggregate preformed seeds and enriched $A \beta$ peptide solutions into monomers and/or low-molecular-weight oligomers (Manzoni et al. 2009). The cells were plated the day before the experiments in completed medium; then, 30 min before the treatment with $A \beta$ peptides, serum-free medium was added to the cells. Treatments of SH-SY5Y with A $\beta$ peptides (1-40 monomers, 1-42 monomers, and 1-42 oligomers) were started $16-18 \mathrm{~h}$ after plating, aliquotes of lyophilized $A \beta$ (monomers or oligomers) were kept at $-80^{\circ} \mathrm{C}$ and dissolved at the time of the experiment as described (Manzoni et al. 2009). MEFs transiently transfected as described above were treated under the same conditions as for SH-SY5Y, $24 \mathrm{~h}$ after transfection. For RNA analysis cells were harvested after 20, 40, $60 \mathrm{~min}$ of treatment, for protein analysis cells were harvested after $1-2-3-6$ or $12 \mathrm{~h}$ of treatment.

\section{Western blot analysis}

Whole-cell extracts were prepared in ice-cold lysing buffer $[1 \mathrm{~mL}$ of phosphate-buffered saline was added with $10 \mu \mathrm{L}$ Triton X100; $10 \mu \mathrm{L}$ SDS $10 \%, 5 \mu \mathrm{L}$ DTT $1 \mathrm{M}, 6 \mu \mathrm{L}$ PMSF $0.1 \%, 10 \mu \mathrm{L}$ aprotinin] for $20 \mathrm{~min}$. The lysates were cleared by centrifugation at $14000 \mathrm{~g}$ for $25 \mathrm{~min}$. Nuclear cell fractions were obtained as previously described by the method of Andrew and Faller (1991). Lysates and nuclear fraction extracts were loaded on 9\% TrisGlycine SDS-PAGE gels and transferred onto PVDF membranes (Amersham Biosciences, Buckingamshire, UK). Non-specific binding was blocked with $50 \mathrm{~g} / \mathrm{L}$ non-fat dry milk in $50 \mathrm{mM}$ Tris- $\mathrm{HCl}$, $\mathrm{pH} 7.4$, containing $200 \mathrm{mM} \mathrm{NaCl}$ and $0.5 \mathrm{mM}$ Tween-20 (Trisbuffered saline Tween). Blots were probed with different primary antibodies, followed by incubation with peroxidase-conjugated antimouse or anti-rabbit immunoglobulins in Tris-buffered saline Tween containing $20 \mathrm{~g} / \mathrm{L}$ non-fat dry milk and the reactive bands were revealed with ECL plus (Amersham Biosciences). To normalize protein levels membranes were stripped with Restore western blot stripping reagent (Pierce, Rockford, IL, USA) and probed with a monoclonal antibody against $\beta$-actin (1:6000; Sigma, St Louis, MO, USA). The following antibodies were used: polyclonal anti-BACE1 (Chemicon, Temecula, CA, USA); antipASK, anti-ASK, anti-pJNKK, anti-JNKK, anti-pJNK, anti-JNK, anti-pc-jun, anti-jun, anti-pERK, and anti-ERK antibodies (Cell Signalling Technology, Beverly, MA, USA).

\section{Quantitative real time PCR analysis}

Total RNA was extracted from 6 wells of cultured cells using the TRIZOL method, according to the manufacturer's protocol (Invitrogen, Carlsbad, CA, USA). Three micrograms of total RNA was reverse transcribed using random primers. Primers and probes for BACE1 were designed with the aid of Primer Express software (Applied Biosystems). To avoid amplification of contaminating genomic DNA, primers and probes were located on adjacent exons. Set primers and probe for BACE1: forward 5'-TGG AGG GCT TCT ACG TTG TCT T- $3^{\prime}$, reverse $5^{\prime}$-GCT GCC GTC CTG AAC TCA TC-3', probe 6fam-5'-TTG GCT TTG CTG TCA GCG CTT GC-3' Tamra. Primers and probes for beta-actin were obtained from a predeveloped assay-on-demand (Applied Biosystems). Five microliters of the resulting cDNA dilution was used for quantitative PCR amplification performed, in duplicate, on the Prism 7900HT Instrument (Applied Biosystems) using the fluorescent TaqMan method. The BACE1 mRNA quantities were normalized to the control gene and were expressed in relation to a calibrator sample. The levels of transcripts BACE1 and $\beta$-actin in each sample were determined using the standard curve. The standard curve was obtained with serial dilutions $\left(10^{6}-10\right.$ molecules) of the calibrator, control plasmids containing cloned sequences of $\mathrm{ABL}$ gene (Ipsogen, Marseille, France).

\section{MTT assay and ROS determination}

For MTT and ROS assays, SH-SY5Y cells were plated and cultured as described above and treated with $A \beta$ species, in a 96-well plate format. Cells were then washed and incubated with MTT solution for $3 \mathrm{~h}$ in incubator (1/10 in culture medium serum free; stock: $5 \mathrm{mg} / \mathrm{mL}$ in PBS; Sigma Chemical Company). Solubilizing solution $(10 \%$ SDS in $0.01 \mathrm{~N} \mathrm{HCl}$ ) was then added (same volume as MTT medium) and incubated over night at $37^{\circ} \mathrm{C}$, on a shaker. The next day wells were read at $570 \mathrm{~nm}$ with background subtraction at $620 \mathrm{~nm}$, using a Benchmark Microplate Reader, with Microplate Manager Version 5.1 Software (Bio-Rad, Hercules, CA, USA).

Intracellular generation of ROS was detected by detecting the conversion of $2^{\prime}, 7^{\prime}$-dichlorodihydrofluorescein diacetate (DCFHDA), internalized by cells and de-acetylated by esterase, into the corresponding fluorescent derivative. Cells were then washed and incubated with $1 \mu \mathrm{L}$ of DCFH-DA $1 \mathrm{mM}$ for $30 \mathrm{~min}$ at $37^{\circ} \mathrm{C}$ (Santa Cruz Biotechnology, Santa Cruz, CA, USA) in $100 \mu \mathrm{L}$ serum-free culture medium without phenol red. After treatment, cells were washed and lysed in $100 \mu \mathrm{L}$ DMSO $90 \%$ and fluorescence was measured on a Fluostar Optima microplate reader (BMG Labtechnologies, Offenburg, Germany; excitation $485 \mathrm{~nm}$, emission $520 \mathrm{~nm})$.

\section{RNA interference}

RNA interference to knockdown the JNK1/2 in MEFs cells were performed using a RNAi human/mouse control kit, including the small RNA duplex (Qiagen, Milan, Italy). The siRNA $(2.5 \mu \mathrm{g})$ were transfected into cells using the proper RNAiFect reagent ratio $(1: 6)$ 
in medium for $48 \mathrm{~h}$. Transfected cells in fresh medium were then exposed to $100 \mathrm{nM} \mathrm{A} \beta 1-42$ for up to $12 \mathrm{~h}$ and then harvested for sample preparation.

\section{Statistical analysis}

Data in bar graphs represent mean $\pm \mathrm{SD}$ and were obtained from average data of at least three independent experiments. Luminograms images are representative of at least three experiments with similar results. Statistical analysis was performed with GraphPad (GraphPad Software Inc., La Jolla, CA, USA), using Student's $t$-test or ANOva test followed by the Bonferroni post-test when appropriate ( $p<0.05$ was considered significant).

\section{Results}

In a previous article (Giliberto et al. 2009), we showed how BACE1 is transcriptionally regulated by soluble A $\beta 1-42$. As reports indicate that $A \beta$ oligomers may have a signaling action, we conducted the same experiments using oligomeric preparations of $A \beta$ compared with monomeric forms (see Figure S1 for a detailed description of different peptide assemblies). We did not used fibrils, as the main effect of
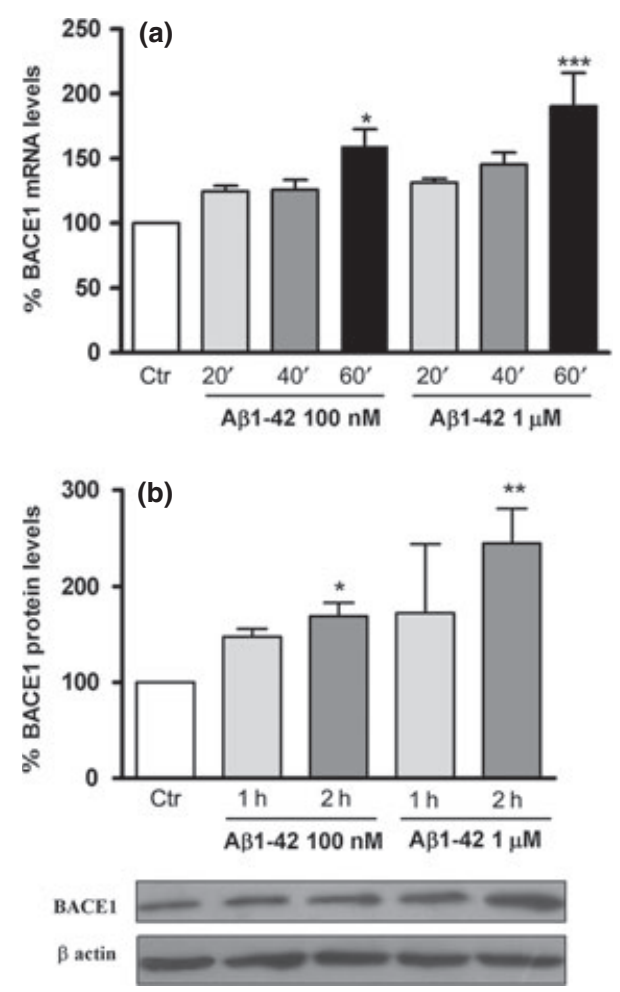

Fig. 1 Effect of monomeric $A \beta 1$ 1-42 on $\beta$-secretase (BACE1) levels on SH-SY5Y neuroblastoma cells. (a) BACE1 mRNA levels increase from 20 min of incubation with monomeric $A \beta \quad 1-42$ and the difference become statistically significant at $1 \mathrm{~h}\left({ }^{*} p<0.05\right.$ for $A \beta 100 \mathrm{nM}$, ${ }^{* * *} p<0.001$ for $A \beta 1 \mu M$ ). (b) BACE1 protein levels increase from $1 \mathrm{~h}$ of incubation with monomeric $A \beta$ 1-42 and the difference become statistically significant at $2 \mathrm{~h}\left({ }^{*} p<0.05\right.$ for $A \beta 100 \mathrm{nM},{ }^{* *} p<0.01$ for $\mathrm{A} \beta 1 \mu \mathrm{M})$. these preparations is toxicity. To obtain reproducible and certain $\mathrm{A} \beta$ conformations, we used a preparation procedure that consists on the sequential use of trifluoroacetic acid, formic acid, and sodium hydroxide solutions that disaggregate preformed seeds and enriched $\mathrm{A} \beta$ peptide solutions into monomers and/or low-molecular-weight oligomers (Manzoni et al. 2009). We used monomeric or oligomeric forms of $\mathrm{A} \beta$ at the lowest possible concentration and for the shortest timeframe: we treated SHSY-5Y cells with $100 \mathrm{nM}$ to $1 \mu \mathrm{M}$ concentrations, for $20-40 \mathrm{~min}$ up to $1-2 \mathrm{~h}$. Monomeric A $\beta$ 1-42 incubation induced BACE1 mRNA level starting from $20 \mathrm{~min}$ incubation and became statistically significant at $1 \mathrm{~h}$ $(* p<0.05$ for $\mathrm{A} \beta 100 \mathrm{nM}, * * * p<0.001$ for $\mathrm{A} \beta 1 \mu \mathrm{M}$; Fig. 1a). This event is paralleled by an augmented protein synthesis induced by monomeric A $\beta$ 1-42 as shown by western blot analysis of BACE1 protein $(* p<0.05$ for $\mathrm{A} \beta$ $100 \mathrm{nM}$, **p $<0.01$ for $\mathrm{A} \beta 1 \mu \mathrm{M}$; Fig. 1b). Thus, we confirm the activation of BACE1 by $\mathrm{A} \beta$ 1-42 at different aggregations states and time points. As control, BACE1 mRNA and protein levels are not affected by treatment with monomeric $A \beta 1-40$ (Fig. 2).
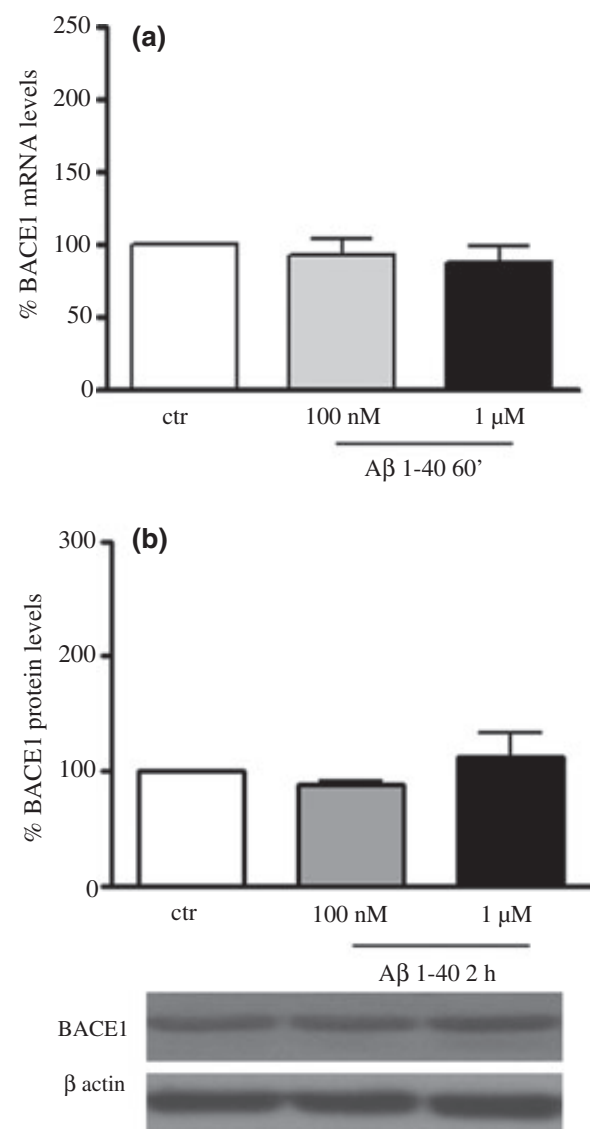

Fig. 2 Effect of monomeric $A \beta 1$-40 on $\beta$-secretase (BACE1) levels on SH-SY5Y neuroblastoma cells. BACE1 mRNA (a) and protein (b) levels do not change after treatment with monomeric $A \beta 1-40100 \mathrm{nM}$ and $1 \mu \mathrm{M}$ even at the longer time frame. 
After having determined the best experimental conditions for monomeric A $\beta$ 1-42-induced BACE1 up-regulation, we ascertained that monomeric $A \beta$ 1-42, as employed in our model, has no toxic effect on the cell. We studied the effect of monomeric $A \beta 1-42$, at the different conditions tested, on SH-SY-5Y neuroblastoma cells viability (MTT assay) and oxidative stress (ROS production), as described before (Tamagno et al. 2008). As positive control, cells have been incubated with oligomeric A $\beta$ 1-42 as soluble oligomers are the toxic form of the peptide, at least at the onset of the pathology (Di Carlo 2010). Monomeric A $\beta$ 1-42 has no effect on cell viability at the different concentrations used (Fig. 3a) nor on ROS production (Fig. 4a) as compared with the oligomeric toxic form (Figs $3 b$ and $4 b$ ). As control, cells viability and oxidative stress are not affected by treatment with monomeric A $\beta$ 1-40 (data not shown).

To investigate the mechanism of BACE1 transcriptional regulation, we focused on the JNK signaling pathway as it can be activated by A $\beta$ peptides (Wang et al. 2004; Kadowaki et al. 2005; Yao et al. 2005). MEFs wild type treated with monomeric A $\beta \quad 1-42 \quad 100 \mathrm{nM}$ showed the activation of JNK and related proteins, e.g. apoptosis signal-regulating kinase 1 (ASK-1), the jun kinase kinase (JNKK), and c-jun (Fig. 5). As JNK and ERK pathways have a dual opposite effect on the expression of BACE 1 (Tamag-
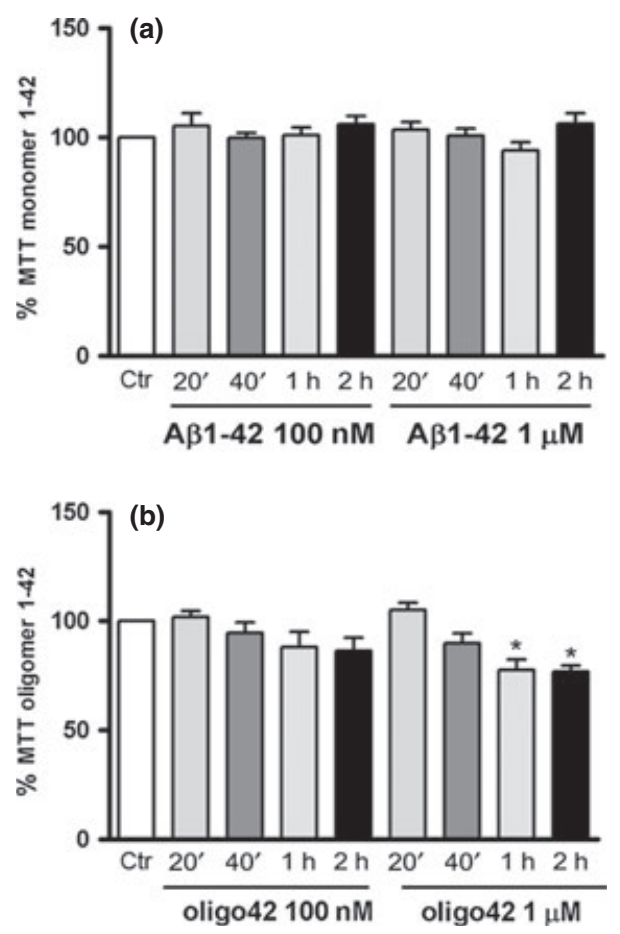

Fig. 3 Effect of $A \beta$ 1-42 on SH-SY-5Y neuroblastoma cells viability (MTT assay). (a) Monomeric A $\beta$ 1-42 has no effect on cell viability at the different concentrations used. (b) Oligomeric $A \beta$ 1-42 is toxic for the cells. Cells viability decreases and the difference becomes statistically significant after $1 \mathrm{~h}$ of incubation with $1 \mu \mathrm{M}$ oligomeric $\mathrm{A} \beta$ $1-42\left({ }^{*} p<0.05\right)$. no et al. 2009), we investigated the effect of $A \beta$ 1-42 on ERK. As expected, treatment with monomeric A $\beta$ 1-42 $100 \mathrm{nM}$ up to $6 \mathrm{~h}$ inhibits the induction of ERK (Fig. 5). Activation of ERK is restored at longer time of exposure, $12 \mathrm{~h}$, when pJNK and pc-jun are down-regulated (Fig. 5).

We then treated MEFs JNK1/2dko with monomeric A $\beta$ 1-42 100nM: basal expression levels of BACE1 are low in these cells (Fig. 6), and monomeric A $\beta$ 1-42 did not change the expression of BACE1 compared to the significant increase induced in the wild type $(* p<0.05$, ** $p<0.01$; Fig. 6). Remarkably, transfection with JNK wild type, but not with a JNK dominant negative construct (Fig. 7), reconstituted the effect of monomeric $\mathrm{A} \beta$ 1-42 on BACE1 expression, as quantified by the relative histograms $(* p<0.05, * * p<0.01)$. Silencing of JNK with RNAi significantly blocked the increase in BACE1 protein levels induced by monomeric $A \beta 1-42$ (Fig. 8), as confirmed by the densitometric analysis $(* * p<0.01)$. These data showed how non-toxic monomeric A $\beta$ 1-42 activates, in a positive feedback loop, the transcription of BACE1, with the activation of the JNK/c-jun pathway.

\section{Discussion}

Our study identifies a physiological function of monomeric A $\beta$ 1-42 able to induce a signaling pathway that leads to
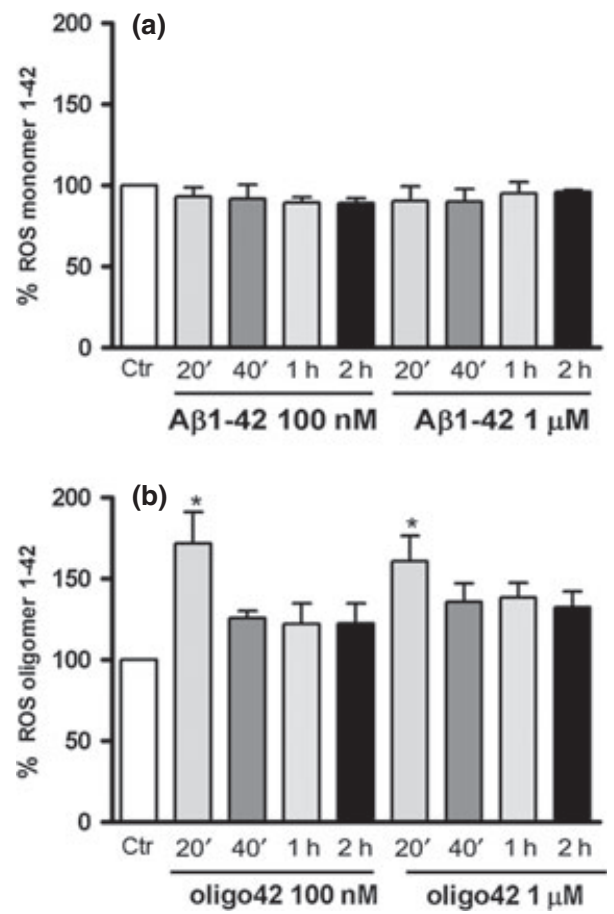

Fig. 4 Effect of $A \beta$ 1-42 on SH-SY-5Y neuroblastoma cells oxidative stress (ROS production). (a) Monomeric $A \beta$ 1-42 has no effect on oxidative stress at the different concentrations used. (b) Oligomeric $A \beta$ $1-42$ is toxic for the cells, oxidative stress is significantly increased $\left({ }^{*} p<0.05\right)$. 

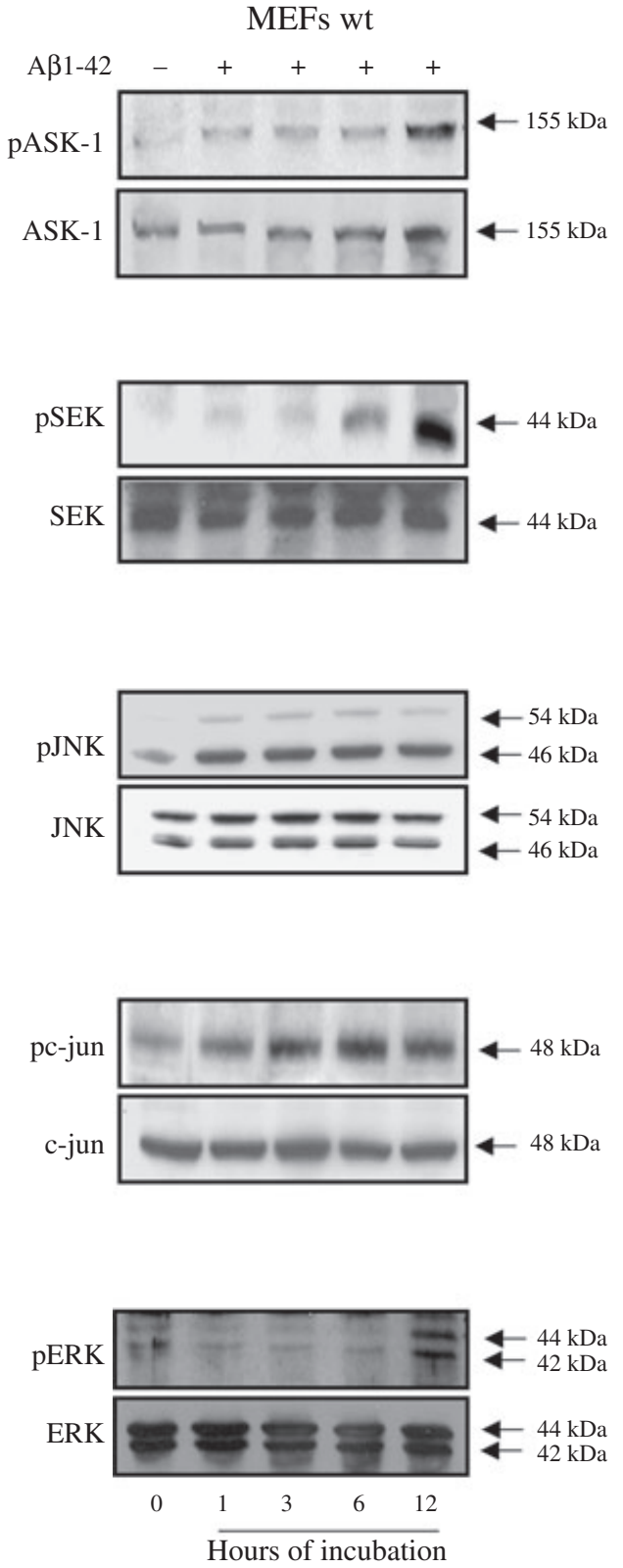


Fig. 5 Effect of monomeric $A \beta$ 1-42 $100 \mathrm{nM}$ on the $\mathrm{c}$-jun $\mathrm{N}$-terminal kinase (JNK) signaling pathway in MEFs wild-type cells. Monomeric A $\beta$ 1-42 $100 \mathrm{nM}$ induces activation of JNK and related proteins, e.g. apoptosis signal-regulating kinase 1 (ASK1 ), the jun kinase kinase (JNKK), and c-jun. As expected $1-6 \mathrm{~h}$ treatment with monomeric $A \beta 1-42100 \mathrm{nM}$ inhibits activation of ERK. ${ }^{*} p<0.05 ;{ }^{* *} p<0.01$. transcriptional activation of BACE1 without causing toxicity to the cell. Previous studies have proposed different physiological functions of A $\beta$ (Kamenetz et al. 2003; Plant et al. 2003). A $\beta$ and BACE1 are pivots of several signaling pathways, involving different cellular receptors and signal transduction mechanisms (Thathiah and De Strooper 2009; Tabaton et al. 2010), leading to heterogeneous cellular effects, from toxicity to synaptic modulation, apoptosis or cell survival (Ulrich et al. 1998; Diarra et al. 2009). A $\beta$ production is dependent on BACE1 (Bennett et al. 2000), but we and others have shown how BACE1 is regulated by soluble $A \beta$ at the transcriptional level, defining a positive control loop that fosters A $\beta$ production (Giliberto et al.
2009; Jo et al. 2010). The specific significance of this regulation is unknown, other than perpetrating the ominous consequences of amyloid accumulation (Liu et al. 2002). APP similarity to NOTCH and to its processing strengthen the idea that APP and its derivatives may have a physiological signaling role. $\mathrm{A} \beta$ binds several ligands and receptors, but the experimental conditions in which synthetic or endogenous $A \beta$ are employed are, again, very heterogeneous (Yaar et al. 2007; Lauren et al. 2009; Tabaton et al. 2010). The hypothesis on A $\beta$ physiological role are heterogeneous and often discordant, as consensus is lacking on its effects at different concentrations, aggregation states, and time of exposure. This could be because of 


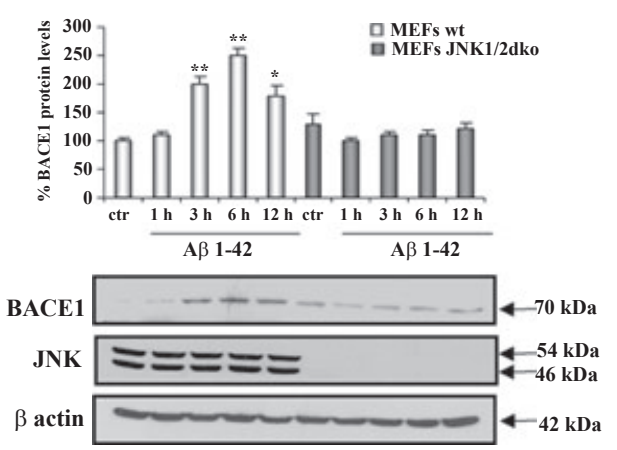

Fig. $6 \beta$-secretase (BACE1) protein levels in MEFs wild type and in MEFs c-jun N-terminal kinase (JNK)1/2dko cells. Basal levels of BACE1 are low in MEFs c-jun N-terminal kinase 1/2dko and monomeric $A \beta$ 1-42 did not change the levels of BACE1 compared to the significant increase induced in the wild type $\left({ }^{*} p<0.05,{ }^{* *} p<0.01\right)$.

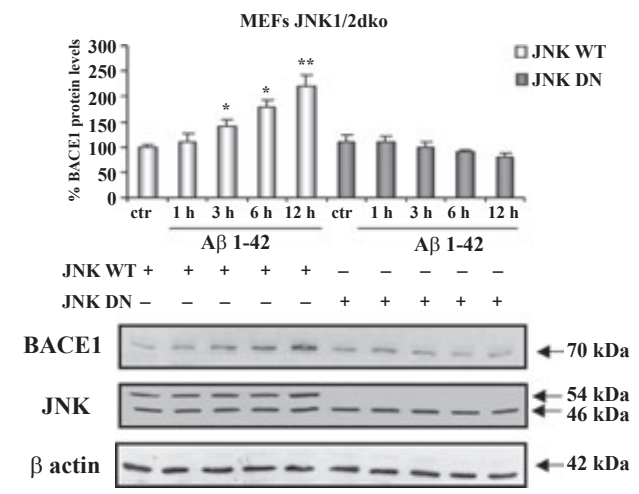

Fig. 7 Effect of c-jun N-terminal kinase (JNK) transfection on $\beta$-secretase (BACE1) expression. Transfection in MEFs JNK1/2dko with JNK wild type (WT) but not with a JNK dominant negative (DN) construct, reconstituted the effect of monomeric $A \beta 1-42$, as quantified by the relative histograms $\left({ }^{*} p<0.05,{ }^{\star *} p<0.01\right)$.

physicochemical and biological variability with different batches of amyloidogenic peptides that have been reported in literature. To avoid this crucial experimental step we used a procedure that enable us to obtain reproducible biological features of $A \beta$ peptides, irrespective to their age (Manzoni et al. 2009). Using this preparation, we showed that monomeric $\mathrm{A} \beta$ is able to trigger BACE1 transcription without affecting cell survival suggesting that the boundary separating toxicity from a probable physiological signaling of $A \beta$ is very narrow. Our results stressed out the importance of the aggregation-dependent biological effect of $\mathrm{A} \beta$ that could be dualistic as it has been reported for its role as either an oxygen radical generator or its inhibitor (Zou et al. 2002).

We showed an induction of BACE1 occurring at low concentrations of monomeric preparations of $A \beta 1-42$ and starting within minutes of treatment. Although this time may seem short, specific gene transcription can occur within



Fig. 8 Silencing of c-jun N-terminal kinase (JNK) with RNAi. The silencing in MEFs wild type of c-jun $\mathrm{N}$-terminal kinase significantly blocked the increase in $\beta$-secretase (BACE1) protein levels induced by monomeric $A \beta 1-42$, as confirmed by the densitometric analysis $\left({ }^{\star *} p<0.01\right)$.

minutes for certain cellular processes (Mira and Castano 1989). It is likely that BACE1 is part of a cellular response aimed at fast adaptation to extracellular stimuli. BACE1 is highly regulated, it is not only the APP $\beta$-secretase. Several secretase and non-secretase functions have been ascribed to BACE1, as the activation of voltage-gated $\mathrm{Na}$ channels (Huth et al. 2009), myelination control and processing molecules other than APP (Lichtenthaler et al. 2003; Wong et al. 2005; Willem et al. 2006). It is thus possible that BACE1, given its complex promoter structure and its relationships with heterogeneous groups of signaling pathways (Sambamurti et al. 2004; Buggia-Prevot et al. 2008; Tamagno et al. 2009), can be part of a pool of enzymes that respond to cellular stress or homeostasis modifications. As in the case of glucose lowering signals, where insulin and metformin have an opposite effect on amyloidogenesis and BACE1 regulation (Chen et al. 2009), in some pathways the same endpoint can results in opposite outcomes on BACE1 activation. This may be because of the fact that BACE1 is working together with still undefined partners to fulfill a cellular response.

As described previously (Guglielmotto et al. 2011), also monomeric $A \beta 1-42$ at non-toxic concentration promotes, in a positive feedback loop, the transcription of BACE1, with the activation of the JNK/c-jun pathway. Although the mechanisms of JNK activation by A $\beta$ 1-42 is still unclear, it is likely that JNK is indirectly activated by $A \beta 1-42$, perhaps by the interaction of $A \beta$ 1-42 with yet unidentified receptors. Indeed, different proteins, such as APP itself, NMDA, TrkA, and LRP family of receptors, have been shown to interact with A $\beta$ peptides (Bu et al. 2006; Lauren et al. 2009). This could lead not only to BACE1 regulation but also to the control of a pool of genes involved in a specific cellular function. The knowledge of the genes activated by $\mathrm{A} \beta$ may 
be determinant to understanding the precise series of events that cause dysfunction and degeneration of neurons in AD.

Our data analyze the functional significance of A $\beta$-induced signaling, its effect on BACE and on other independent pathways and have implications on the pathogenesis of $\mathrm{AD}$, in terms of understanding these pathways all the way toward the specific cellular receptors involved. Consequently, the study may indicate strategies of therapy different from those only focused on halting the accumulation of $A \beta$ in the brain. Furthermore, defining the network of genes in which BACE1 is called in to operate, in response to amyloidogenic stimuli, will allow to better understand its still unclear function and find ways to safely modulate its activity.

\section{Acknowledgements}

The study was supported by grants of Italian Minister of Health (Dr Tabaton), the CARIGE Foundation (Dr Tabaton), the CARIPLO Foundation (Dr Cammarata), and Banca Intesa Sanpaolo (Dr Salmona). The kind gift of FMOC aminoacids by Flamma Spa (Bergamo, Italy) is gratefully acknowledged. Authors have no conflict of interest to declare.

\section{Supporting information}

Additional supporting information may be found in the online version of this article:

Figure S1. Analysis of the molecular assemblies of monomeric and oligomeric forms of $A \beta$ 1-42.

As a service to our authors and readers, this journal provides supporting information supplied by the authors. Such materials are peer-reviewed and may be re-organized for online delivery, but are not copy-edited or typeset. Technical support issues arising from supporting information (other than missing files) should be addressed to the authors.

\section{References}

Abramov E., Dolev I., Fogel H., Ciccotosto G. D., Ruff E. and Slutsky I. (2009) Amyloid-beta as a positive endogenous regulator of release probability at hippocampal synapses. Nat. Neurosci. 12, 15671576.

Andrew N. C. and Faller D. V. (1991) A rapid micropreparation technique for extraction of DNA-binding proteins from limiting numbers of mammalian cells. Nucleic Acids Res. 19, 2499.

Bennett B. D., Denis P., Haniu M., Teplow D. B., Kahn S., Louis J. C., Citron M. and Vassar R. (2000) A furin-like convertase mediates propeptide cleavage of BACE, the Alzheimer's beta-secretase. J. Biol. Chem. 27, 37712

Borghi R., Patriarca S., Traverso N., Piccini A., Storace D., Garuti A., Cirmena G., Odetti P. and Tabaton M. (2007) The increased activity of BACE1 correlates with oxidative stress in Alzheimer's disease. Neurobiol. Aging 28, 1009-1014.

Bu G., Cam J. and Zerbinatti C. (2006) LRP in amyloid-beta production and metabolism. Ann. NY Acad. Sci. 1086, 35-53.

Buggia-Prevot V., Sevalle J., Rossner S. and Checler F. (2008) NFkappaB-dependent control of BACE1 promoter transactivation by Abeta42. J. Biol. Chem. 283, 10037.
Bulbarelli A., Lonati E., Cazzaniga E., Re F., Sesana S., Barisani D., Sancini G., Mutoh T. and Masserini M. (2009) TrkA pathway activation induced by amyloid-beta (Abeta). Mol. Cell. Neurosci. 40, 365-373.

Chauhan V. and Chauhan A. (2006) Oxidative stress in Alzheimer's disease. Pathophysiology 13, 195-208.

Chen Y., Zhou K., Wang R. et al. (2009) Antidiabetic drug metformin (GlucophageR) increases biogenesis of Alzheimer's amyloid peptides via up-regulating BACE1 transcription. Proc. Natl. Acad. Sci. U S A 106, 3907.

Citron M., Westaway D., Xia W. et al. (1997) Mutant presenilins of Alzheimer's disease increase production of 42-residue amyloid beta-protein in both transfected cells and transgenic mice. Nat. Med. 3, 67-72.

Di Carlo M. (2010) Beta amyloid peptide: from different aggregation forms to the activation of different biochemical pathways. Eur. Biophys. J. 39, 877-888.

Diarra A., Geetha T., Potter P. and Babu J. R. (2009) Signaling of the neurotrophin receptor p75 in relation to Alzheimer's disease. Biochem. Biophys. Res. Commun. 390, 352.

Giliberto L., Borghi R., Piccini A. et al. (2009) Mutant presenilin 1 increases the expression and activity of BACE1. J. Biol. Chem. 284, 9027-9038.

Gobbi M., Colombo L., Morbin M. et al. (2006) Gerstmann-SträusslerScheinker disease amyloid protein polymerizes according to the "Dock-and-Lock" model. J. Biol. Chem. 281, 843-849.

Guglielmotto M., Monteleone D., Giliberto L., Fornaro M., Borghi R., Tamagno E. and Tabaton M. (2011) Amyloid- $\beta 42$ activates the expression of BACE1 through the JNK pathway. J. Alzheimers Dis. 26, 1-13.

Holsinger R. M., McLean C. A., Beyreuther K., Masters C. L. and Evin G. (2002) Increased expression of the amyloid precursor betasecretase in Alzheimer's disease. Ann. Neurol. 51, 783-786.

Huth T., Schmidt-Neuenfeldt K., Rittger A., Saftig P., Reiss K. and Alzheimer C. (2009) Non-proteolytic effect of beta-site APPcleaving enzyme 1 (BACE1) on sodium channel function. Neurobiol. Dis. 33, 282.

Jo D. G., Arumugam T. V., Woo H. N. et al. (2010) Evidence that gamma-secretase mediates oxidative stress-induced beta-secretase expression in Alzheimer's disease. Neurobiol. Aging 31, 917-925.

Kadowaki H., Nishitoh H., Urano F. et al. (2005) Amyloid beta induces neuronal cell death through ROS-mediated ASK1 activation. Cell Death Differ. 12, 19-24.

Kamenetz F., Tomita T., Hsieh H., Seabrook G., Borchelt D., Iwatsubo T., Sisodia S. and Malinow R. (2003) APP processing and synaptic function. Neuron 37, 925-937.

Kao S. C., Krichevsky A. M., Kosik K. S. and Tsai L. H. (2004) BACE1 suppression by RNA interference in primary cortical neurons. J. Biol. Chem. 279, 1942-1949.

Kirkitadze M. D. and Kowalska A. (2005) Molecular mechanisms initiating amyloid beta-fibril formation in Alzheimer's disease. Acta Biochim. Pol. 52, 417-423.

Lauren J., Gimbel D. A., Nygaard H. B., Gilbert J. W. and Strittmatter S. M. (2009) Cellular prion protein mediates impairment of synaptic plasticity by amyloid-beta oligomers. Nature 457, 1128-11132.

Lichtenthaler S. F., Dominguez D. I., Westmeyer G. G., Reiss K., Haass C., Saftig P., De Strooper B. and Seed B. (2003) The cell adhesion protein P-selectin glycoprotein ligand-1 is a substrate for the aspartyl protease BACE1. J. Biol. Chem. 278, 48713.

Liu K., Doms R. W. and Lee V. M. (2002) Glu11 site cleavage and N-terminally truncated A beta production upon BACE overexpression. Biochemistry 41, 3128.

Maloney B. and Lahiri D. K. (2011) The Alzheimer's amyloid $\beta$-peptide $(\mathrm{A} \beta)$ binds a specific DNA $\mathrm{A} \beta$-interacting domain $(\mathrm{A} \beta \mathrm{ID})$ in the 
APP, BACE1, and APOE promoters in a sequence-specific manner: characterizing a new regulatory motif. Gene 488, 13-22.

Manzoni C., Colombo L., Messa M., Cagnotto A., Cantu L., Del Bavero E. and Salmona M. (2009) Overcoming synthetic Abeta peptide aging: a new approach to an age-old problem. Amyloid 16, 71-80.

Mira E. and Castano J. G. (1989) Insulin short-term control of rat liver alpha 2-microglobulin gene transcription. J. Biol. Chem. 264, 18209-18212.

Parri R. H. and Dineley T. K. (2010) Nicotinic acetylcholine receptor interaction with beta-amyloid: molecular, cellular, and physiological consequences. Curr. Alzheimer Res. 7, 27-39.

Plant L. D., Boyle J. P., Smith I. F., Peers C. and Pearson H. A. (2003) The production of amyloid beta peptide is a critical requirement for the viability of central neurons. J. Neurosci. 23, 5531-5535.

Sambamurti K., Kinsey R., Maloney B., Ge Y. W. and Lahiri D. K. (2004) Gene structure and organization of the human beta-secretase (BACE) promoter. FASEB J. 18, 1034-1036.

Selkoe D. J. (2001) Alzheimer's disease: genes, proteins, and therapy. Physiol. Rev. 81, 741-766.

Sun X., He G., Qing H., Zhou W., Dobie F., Cai F., Staufenbiel M., Huang L. E. and Song W. (2006) Hypoxia facilitates Alzheimer's disease pathogenesis by up-regulating BACE1 gene expression. Proc. Natl. Acad. Sci. U S A 103, 18727-18732.

Tabaton M., Zhu X., Perry G., Smith M. A. and Giliberto L. (2010) Signaling effect of amyloid-beta(42) on the processing of AbetaPP. Exp. Neurol. 221, 18-25.

Tamagno E., Bardini P., Obbili A. et al. (2002) Oxidative stress increases expression and activity of BACE in NT2 neurons. Neurobiol. Dis. 10, 279-288.

Tamagno E., Guglielmotto M., Aragno M. et al. (2008) Oxidative stress activates a positive feedback between the gamma- and beta-secretase cleavages of the beta-amyloid precursor protein. J. Neurochem. 104, 683-695.

Tamagno E., Guglielmotto M., Giliberto L., Vitali A., Borghi R., Autelli R., Danni O. and Tabaton M. (2009) JNK and ERK1/2 pathways have a dual opposite effect on the expression of BACE1. Neurobiol. Aging 30, 1563-1573.

Thathiah A. and De Strooper B. (2009) G protein-coupled receptors, cholinergic dysfunction, and Abeta toxicity in Alzheimer's disease. Sci Signal 2, re8.

Townsend M., Mehta T. and Selkoe D. J. (2007) Soluble Abeta inhibits specific signal transduction cascades common to the insulin receptor pathway. J. Biol. Chem. 282, 33305-33312.
Ulrich E., Duwel A., Kauffmann-Zeh A., Gilbert C., Lyon D., Rudkin B., Evan G. and Martin-Zanc D. (1998) Specific TrkA survival signals interfere with different apoptotic pathways. Oncogene 16, 825 .

Verdier Y., Zarándi M. and Penke B. (2004) Amyloid beta-peptide interactions with neuronal and glial cell plasma membrane: binding sites and implications for Alzheimer's disease. J. Pept. Sci. 10, 229-248.

Wang Q., Walsh D. M., Rowan M. J., Selkoe D. J. and Anwyl R. (2004) Block of long-term potentiation by naturally secreted and synthetic amyloid beta-peptide in hippocampal slices is mediated via activation of the kinases c-Jun N-terminal kinase, cyclin-dependent kinase 5, and p38 mitogen-activated protein kinase as well as metabotropic glutamate receptor type 5. J. Neurosci. 24, 33703378.

Willem M., Garratt A. N., Novak B., Citron M., Kaufmann S., Rittger A., DeStrooper B., Saftig P., Birchmeier C. and Haass C. (2006) Control of peripheral nerve myelination by the beta-secretase BACE1. Science, 314, 664.

Wong H. K., Sakurai T., Oyama F., Kaneko K., Wada K., Miyazaki H., Kurosawa M., De Strooper B., Saftig P. and Nukina N. (2005) beta Subunits of voltage-gated sodium channels are novel substrates of beta-site amyloid precursor protein-cleaving enzyme (BACE1) and gamma-secretase. J. Biol. Chem. 280, 23009.

Yaar M., Zhai S., Panova I., Fine R. E., Eisenhauer P. B., Blusztajn J. K., Lopez-Coviella I. and Gilchrest B. A. (2007) A cyclic peptide that binds $\mathrm{p} 75(\mathrm{NTR})$ protects neurones from beta amyloid (1-40)-induced cell death. Neuropathol. Appl. Neurobiol. 33, 533.

Yan S. D., Bierhaus A., Nawroth P. P. and Stern D. M. (2009) RAGE and Alzheimer's disease: a progression factor for amyloid-beta-induced cellular perturbation? J. Alzheimers Dis. 16, 833-843.

Yang L. B., Lindholm K., Yan R. et al. (2003) Elevated beta-secretase expression and enzymatic activity detected in sporadic Alzheimer disease. Nat. Med. 9, 3-4.

Yao M., Nguyen T. V. and Pike C. J. (2005) Beta-amyloid-induced neuronal apoptosis involves c-Jun $\mathrm{N}$-terminal kinase-dependent downregulation of Bcl-w. J. Neurosci. 25, 1149-1158.

Zou K., Gong J. S., Yanagisawa K. and Michikawa M. (2002) A novel function of monomeric amyloid beta-protein serving as an antioxidant molecule against metal-induced oxidative damage. J. Neurosci. 22, 4833-4841. 